\title{
Bellier Turbidity Temperature Test (BTTT) using for Identification of safflower oil available in markets of India
}

\author{
Shashikant Pardeshi*
}

DPHL,Jalgaon,Maharashtra,India

\begin{abstract}
In this study an attempt has been made to investigate the applicability of BTTT to safflower oils obtained from different parts of India and thereby examine the influence of geographical variations on BTTT. The BTTT method is cheaper, easier, requires little laboratory infrastructure and recognised as a convenient qualitative tool for identification of different variety of oils. In the present work, the safflower oils used for analysis, such as safflower oil (sf,(14.8), Purevera), kacchi ghani safflower oil (kgsf,(15.9), Girin), kardai ghani oil (kg,(15.8), Jijau) and cold pressed safflower oil (cpsf, (15.4),Indic wisdom),wood pressed safflower oil(wpsf,(15.9),Satvyk),safflower ghani oil(sfg,(15.6), Suncity)exhibited BTT in the range of 14.8 to $15.9^{0} \mathrm{C}$. The result have demonstrated the reproducibility through the analyzed data. Hence It is observed that safflower oil fulfils BTTT values as per Hence It is observed that safflower oil fulfils BTTT values as per Food Safety Standards and Act 2006 of (Food Products and Standards and food additives) Regulation 2011.The standard mean error is in between 0.09-0.15 in case of BTT.
\end{abstract}

Keywords: Vegetable oil, safflower seed oil, Identification ,BTTT.

\section{Introduction and objective}

Safflower is one of the most important oil crops in the world because of its high quality nutritional composition and it is common source of edible oil. It has excellent variability for seed oil content and fatty acid composition. The oil content of the safflower at maturity is known to vary among cultivars and crop improvement programme have expended a great effort to increase the oil content in the mature seeds of modern cultivars; thus, high oil content breeding is a primary improvement strategy for improving the oil yield in Safflower. The safflower is replaced linseed oil in most organic coatings in some circumstances with advantage.[1] The oil can be used for cooking, illuminating or soap manufacture. [2] On accounting of its good drying properties, safflower oil is also used for the manufacture of paints, varnishes, linoleum, glass-cement etc.[3] The oil is useful in rheumatism and hypertension. [4,5]

The quality of fats and oils is dictated by several physical such as texture, density, pacific gravity, colour, refractive index etc and chemical parameters such as acid value, iodine value, saponification value, unsaponifable matter BTT etc are dependent on the source of oil; geographic, climatic, and agronomic variables of growth. Thus one must assess quantitatively the influence of these variables on characteristics of oils and fats; in present case on characteristics of safflower oil, Bellier Turbidity Temperature Test (BTTT) (acetic acid method), based on insolubility of Arachidic $\operatorname{acid}(0.37 \%)$ is used as a qualitative method for identification of pure safflower oil. Moreover safflower seed from different geographical locations differs in oil content (27-32\%). The Bellier figure or the temperature at which turbidity appears in a specified and neutralised oil sample under specified conditions was first proposed by Bellier and modified by several workers including Franz and Adler. According to Ever in 1912, the addition of sufficient acetic acid used instated of $1 \%$ hydrochloric acid succeeding modifications in the BTT[6].

The objective of the present studies was to investigate and analyse the applicability of important parameter BTTT to different brands of commercial safflower oils obtained from different parts of India and thereby examine the influence of geographical variations on BTTT as tool for identification of safflower oil, to assess the quality and compared the assessed value with existing standards of BTTT for the respective oils as per Food safety and standards (food products and additives) Regulation 2011. 


\subsection{Literature review}

Worldwide the primary use for safflower is edible seed oil for use in cooking, salad oils and margarine. The meal left over after extraction of oils from seeds can be used as a stockfeed for cattle and other livestock. The meal is unsuitable for monogastric animals such as swine and poultry, due to hulls not being removed resulting in a high fibre content (30$40 \%$ ). Cultivated varieties of safflower range in seed oil content from $20-45 \%$ of the whole seed [7]. There are two groups of safflower cultivars differing in seed oil composition, characterised by high linoleic acid (70-75\% of total fatty acids) and high oleic acid (70-75\%)[8].Commercial safflower cultivars grown in Australia are either those high in the monounsaturated fatty acid, oleic acid or those high in the polyunsaturated fatty acid, linoleic acid. The safflower varieties that are high in oleic oil are used as heat stable cooking oil, cosmetics and infant food formulations. The linoleic oil varieties contain nearly $75 \%$ linoleic acid which is used for edible oil products such as salad oils and soft margarines [9].Public awareness about the health benefits of certain fatty acids has already made safflower an important crop for the vegetable oil market [7].

The solubility of oils in various solvents is a constant, depending on the nature of the glycerides composing the oil. Fryer and Weston found that a mixture of equal volume of $92 \%$ ethyl alcohol and pure amyl alcohol used as a solvent for turbidity. In Valenta test, acetic acid was used as a solvent, the results are affected by the presence of moisture in the oil and free fatty acid which lower the turbidity temperature, increasing the solubility of the oils, which raises the turbidity temperature [6].

The modified BTT test has been used by Ever for judging the purity of oils and has been found simple, rapid and fairly accurate for routine analysis as compared to the results obtained by Valenta test. Moreover, it can be conveniently used in the analysis of soap and commercial fatty acids and also for determining the $\%$ of two mixed oils. Others workers have also successfully used the same test for determining adulteration of safflower oil in some edible oils and also suggested its analytical importance. Besides the turbidity temperatures obtained with fatty acids by the method of fryer and Weston are different from those for the respective oils, depending on the difference in the solubility of the glycerides of the oil and its fatty acids in the same solvent [10].

Table-1 Shows BTT standards/values for some edible vegetable oils under 2.2: Fats, oils and Fat emulsions as per FSSA 2006[12]

\begin{tabular}{|c|c|c|c|}
\hline $\begin{array}{l}\mathrm{N} \\
\mathrm{o}\end{array}$ & Item No & Vegetable oil & $\begin{array}{l}\text { BTT } \\
\text { limits }\end{array}$ \\
\hline 1 & 2.2 .1 .2 & Cotton seed oil & $\begin{array}{ll}19.0 & - \\
21.0^{\circ} \mathrm{C} & \end{array}$ \\
\hline 2 & 2.2.1.3 & groundnuts oil & $\begin{array}{l}39.0^{-} \\
41.0^{0} \mathrm{C}\end{array}$ \\
\hline 3 & 2.2 .1 .6 & $\begin{array}{l}\text { Rape seed oil } \\
\text { Mustard oil (toria } \\
\text { oil) }\end{array}$ & $\begin{array}{l}23.0-27.5 \\
{ }^{0} \mathrm{C}\end{array}$ \\
\hline 4 & 2.2 .1 .7 & $\begin{array}{l}\text { Rape seed oil or } \\
\text { Mustard oil-Low } \\
\text { erucic acid }\end{array}$ & $\begin{array}{l}\text { Not more } \\
\text { than } \\
19.0^{0} \mathrm{C}\end{array}$ \\
\hline \multirow[t]{2}{*}{5} & \multirow[t]{2}{*}{2.2 .1 .8} & Virgin olive oil & $\begin{array}{l}17.0^{\circ} \mathrm{C} \\
\operatorname{Max}\end{array}$ \\
\hline & & Refined olive oil & $\begin{array}{l}17.0^{\circ} \mathrm{C} \\
\operatorname{Max}\end{array}$ \\
\hline 6 & 2.2 .1 .10 & $\begin{array}{l}\text { Safflower seed oil } \\
\text { (barrey ka tel) }\end{array}$ & $\begin{array}{l}\text { Not more } \\
\text { than } \\
16.0^{0} \mathrm{C}\end{array}$ \\
\hline 7 & 2.2 .1 .12 & $\begin{array}{l}\text { Til oil } \\
\text { (Gingelly/safflow } \\
\text { er oil) }\end{array}$ & $\begin{array}{l}\text { Not more } \\
\text { than } \\
22.0^{0} \mathrm{C}\end{array}$ \\
\hline 8 & 2.2 .1 .13 & $\begin{array}{l}\text { Niger seed oil } \\
\text { (sargiya ka tel) }\end{array}$ & $\begin{array}{l}25.0^{-} \\
29.0^{0} \mathrm{C}\end{array}$ \\
\hline 9 & 2.2 .1 .17 & Almond oil & $\begin{array}{l}\text { Not more } \\
\text { than } \\
60.0^{0} \mathrm{C}\end{array}$ \\
\hline
\end{tabular}

\subsection{Material and Experimental procedures}

1.3.1 Materials

All the chemicals and reagents were analytical grade and used as received. Four safflower oils of different brands such as safflower oil (sf, Purevera), kacchi ghani safflower oil (kgsf, Girin), kardai ghani oil (kg, Jijau) and cold pressed safflower oil (cpsf, Indic wisdom), wood pressed safflower oil(wpsf, Satvyk),safflower ghani oil(sfg, Suncity) were gathered from super market of different places of India. Since these four safflower oils were easily available for procurement. All these oils were in different forms of packaging while some in poly packs (HDPE), others were in tetra packs, plastic cans and pet bottles of 1 litres and 5 litres. These different safflower oils are used in the investigations on BTTT in this research study.

\subsection{Experimental procedures}

\subsubsection{Determination of Bellier turbidity temperature acetic acid Method}

Pipette out one $\mathrm{ml}$ of the filtered sample of oil in a flat-bottom $100 \mathrm{ml}$ round flask, add $5 \mathrm{ml}$ of $1.5 \mathrm{~N}$ alcoholic potash heating over a boiling water bath using an air condenser After complete saponification cooling, neutralised by adding 
carefully dilute acetic acid and then add an extra amount of $0.4 \mathrm{ml}$ of accurately measured dilute acetic acid using phenolphthalein indicator. Add 50 $\mathrm{ml}$ of $70 \%$ alcohol and mixed well. Heat and allow the flask to cool in air with frequent shaking. Note the temperature by using calibrated thermometer at which the first distinct turbidity appears which is the turbidity temperature. This turbidity temperature is confirmed by a little further cooling which results in deposition of the precipitate. Dissolve the precipitate by heating the contents to $50^{\circ} \mathrm{C}$ over water bath, again cool as desiccated above and make a triplicate determination of the turbidity temperature $[\mathbf{1 1}, \mathbf{1 3}]$.

Table 2: BTTT of different safflower oils with accuracy on BTT

\begin{tabular}{|c|c|c|c|c|c|c|}
\hline $\begin{array}{l}\text { Nam } \\
\text { e of } \\
\text { oil }\end{array}$ & $\begin{array}{l}\text { Brand } \\
\text { name }\end{array}$ & $\begin{array}{l}\text { Co } \\
\text { de }\end{array}$ & $\begin{array}{l}\text { BTT } \\
\mathrm{T}^{*}\end{array}$ & SD & $\mathrm{CV}$ & SEM \\
\hline $\begin{array}{l}\text { saffl } \\
\text { ower } \\
\text { oil }\end{array}$ & $\begin{array}{l}\text { Purever } \\
\text { a }\end{array}$ & sf & 14.8 & 0.17 & 1.49 & 0.09 \\
\hline $\begin{array}{l}\text { kacch } \\
\text { i } \\
\text { ghani } \\
\text { safflo } \\
\text { wer } \\
\text { oil }\end{array}$ & Girin & $\begin{array}{l}\mathrm{kgs} \\
\mathrm{f}\end{array}$ & 15.9 & 0.26 & 1.64 & 0.15 \\
\hline $\begin{array}{l}\text { kardai } \\
\text { ghani } \\
\text { oil }\end{array}$ & Jijau & $\mathrm{kg}$ & 15.8 & 0.26 & 1.65 & 0.15 \\
\hline $\begin{array}{l}\text { cold } \\
\text { presse } \\
\text { d } \\
\text { safflo } \\
\text { wer } \\
\text { oil } \\
\end{array}$ & $\begin{array}{l}\text { Indic } \\
\text { wisdom }\end{array}$ & $\begin{array}{l}\text { cps } \\
\mathrm{f}\end{array}$ & 15,4 & 0.17 & 1.1 & 0.09 \\
\hline $\begin{array}{l}\text { wood } \\
\text { presse } \\
\text { d } \\
\text { safflo } \\
\text { wer } \\
\text { oil }\end{array}$ & Satvyk & $\begin{array}{l}\text { wps } \\
\text { f }\end{array}$ & 15.9 & 0.26 & 1.64 & 0.15 \\
\hline $\begin{array}{l}\text { safflo } \\
\text { wer } \\
\text { ghani } \\
\text { oil }\end{array}$ & Suncity & $\mathrm{sfg}$ & 15.6 & 0.26 & 1.67 & 0.15 \\
\hline
\end{tabular}

* Each value is averages of three measurements, SD-standard deviation, CV-coefficient of variance, SEM-standard mean error

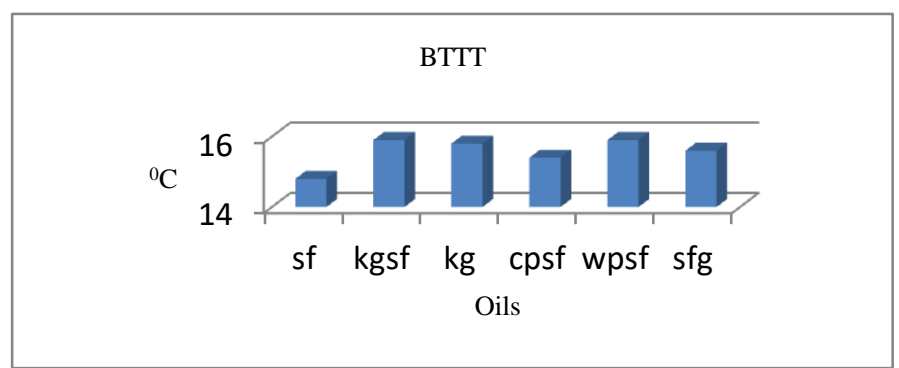

Fig.1 shows the BTTT values for different safflower oil

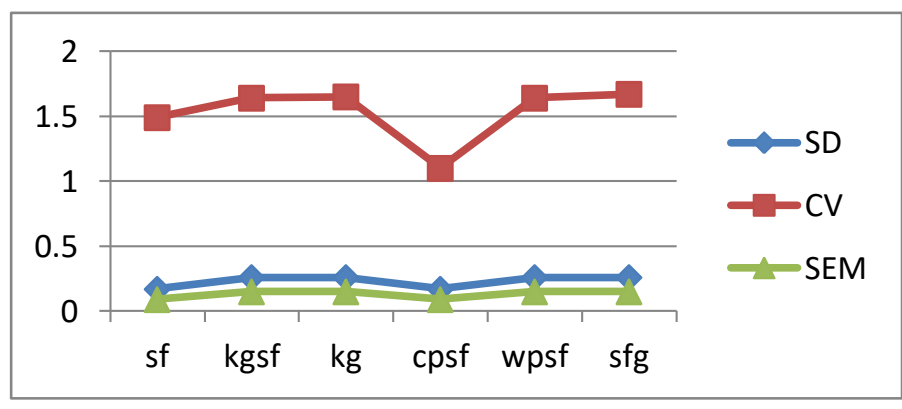

Fig.2 showed the statistical values for different safflower oil

\subsection{Statistical analysis:}

The data obtained from the experimental measurements and accuracy of BTTT for different brands of safflower oils have been analyzed and the Statistical parameter like standard deviation, coefficient of variance and standard mean error were calculated for both the parameters. All the experiment was carried out in triplicate and the results are presented as the mean SD, CV and SEM. Descriptive Statistics of different safflower oils from different parts of India as shown in figure1 and 2.

\subsection{Result and discussion}

BTT values prescribed for the certain vegetable oils comes under the mandatory food laws in some countries but due to development towards hybridization in oil seeds, reconsideration in laws is required. Table-1 Showed the BTT standards/values for some edible vegetable oils under 2.2: Fats, oils and Fat emulsions as per FSSA 2006[12]. The results obtained for the BTTT and statistical accuracy for the safflower oils obtained from different places of India are shown in Table2, Fig 1 and Fig 2. The data obtained for safflower oil such as sf (14.8), $\mathrm{kgsf}(15.9 \quad), \mathrm{kg}(15.8)$, cpsf (15.4), wpsf (15.9) and sfg (15.6) are exhibited BTT not more than $16^{\circ} \mathrm{Cin}$ the range of $\left(14.8\right.$ to $\left.15.9^{\circ} \mathrm{C}\right)$. As all the reported BTTT values are average of three readings, the results have demonstrated the reproducibility of 
the analysis data. Thus the present investigations prove with due certainty the applicability of BTTT to all safflower oils. Table 2 shows the accuracy, the standard deviation and coefficient is in the range of $0.17-0.26$ and $1.1-1.67$.

\subsection{Future prospects}

Wherever required, BTTT analysis, Quantitative test should essential and can be easily supplemented with GC and HPLC analysis, which provide the quantitative data on presence of high molecular weight fatty acids in safflower oils. Hence BTTT depends on the presence of arachidic acid and other higher acids in safflower oil.

\subsection{Conclusion}

The BTTT method is cheaper, easier, requires little laboratory infrastructure and recognised as a convenient qualitative tool for identification of different variety of oils. In this study BTTT is applied on safflower oils and found that BTTT can be easily used as qualitative tool for identification of purity of safflower oil from different places of India. The present investigations prove with due certainty about applicability of BTTT to all safflower oils. This study also confirms prove reliability, reproducibility and diverse applicability of BTTT.

\section{References}

[1] Pugsby and Winter, Indian Soap J, loc. Cit.II ,807(1956).

[2] Gholam Mawla, N. M. Sheik and A. S. M. Kamal. A hand book of edible oils and fats, $1^{\text {st }}$ Ed. July, 183(1990).
[3] K. N. Ninan, Edible oil seeds, 1st Ed.108 and 109(1987).

[4] Kaliphodo Biswas and Shree Eq Kori Ghoes., Bharotiyo Bonushudhy, $2^{\text {nd }}$. Ed. $3^{\text {rd }}$ part,639(1950).

[5] Rafiquzzaman, M. Altaf Hossain and AJM Moynul Hasan ,Studies on the Characterization and Glyceride Composition of Safflower (Carthamus tinctorius)Seed Oil, Bangladesh J. Sci. Ind. Res. 41(3-4),235-238(2006).

[6] Norman Evers., The detection of archis oil in olive and almond oil, Analyst, 62:96(1936).

[7] Dajue, L., and Mündel, H.H,Safflower. Carthamus tinctoriusL.,7 (Institute of Plant Genetics and Crop Plant Research, Gatersleben /International Plant Genetic Resources Institute, Rome.) (1996).

[8] Singh, V., and Nimbkar, N.,Safflower (Carthamus tinctoriusL.).In Genetic Resources, Chromosome Engineering, and Crop Improvement: Oilseed Crops (CRC Press), 167-194(2006).

[9] GRDC, Raising the bar with better safflower agronomy :Grains Researchand Development Corporation(2010).

[10] Desai C.M, Turbidity Temperature of oils as determines by Belier'sTest Its significance as an Analytical constant, current science, 16(3), 9294(1947).

[11] Directorate General of Health Services, Manual of methods of analysis of foods (Oils and Fats) Food Safety and Standards Authority of India (FSSAI),Ministry of health and family Welfare, Government of India, New Delhi(2012).

[12] Food safety and standards Act 2006, Rules 2008, Regulations $2011,8^{\text {th }}$ edition, Professional book publishers, New Delhi, India(2014).

[13] Indian Institution of standards, Bellier Turbidity Test, Handbook of food analysis and (part XIII)90(1984). 